\title{
Removal of Pollutants from Water/Waste Water Using Nano-Adsorbents: A Potential Pollution Mitigation
}

\author{
B.L. Dinesha*, H. Sharanagouda, N. Udaykumar, \\ C.T. Ramachandr and Anil B. Dandekar \\ Department of Processing and Food Engineering, College of Agricultural Engineering, \\ University of Agricultural Sciences, Raichur- 584 104, Karnataka, India \\ *Corresponding author
}

\author{
A B S T R A C T
}

\begin{tabular}{|l|}
\hline Ke y w o r d s \\
Nanotechnology, \\
Nano-adsorbents, \\
Pollutants and \\
Wastewater.
\end{tabular}

Nano-adsorbents have gained special attention in water pollution mitigation in India since last decade. Two vital properties make nanoparticles highly lucrative as adsorbents. On a mass basis, nano-particles have much larger surface areas compared to macro particles. They can also be enhanced with various reactor groups to increase their chemical affinity towards target compounds. Nano-adsorption techniques are now widely used to remove cations, natural organic matter, biological contaminants, inorganic pollutants, nitrates and arsenic from groundwater, surface water and industrial effluents. Nano-adsorbents of mixed oxides such as iron-cerium, iron-manganese, iron-zirconium, iron-titanium, ironchromium, cerium-manganese were successfully employed for water treatment. Among the available different technologies, adsorption is one of the best due to its easy handling, low cost and high efficiency. The environmental fate and toxicity of a material are critical issues in materials selection and design for wastewater purification system. The success of the nanotechnology in field conditions is a factor of interdisciplinary works, which need successful collaboration of chemistry, material science and geology and biosciences.

\section{Introduction}

Water is a fundamental substance whose material existence is secondary compared to the symbolic value as it is manifested in our mind as the symbol of life. Sustainable supplies of clean water are vital to the world's health, environment and economy (Bhattacharya et al., 2013). Water has a broad impact on all aspects of human life including but not limited to health, food, energy and economy (Amin et al., 2014). It is estimated that 10-20 million people die every year due to waterborne and nonfatal infection causes death of more than 200 million people every year (Leonard et al., 2003).
Every day about 5,000-6,000 children die due to the water-related problem of diarrhea (Ashbolt 2004; Hutton et al., 2007). There are currently more than 0.78 billion people around the world who do not have access to safe water resources (WHO, 2013) resulting in major health problems. It is estimated that more than one billion people in the world lack access to safe water and within couple of decades the current water supply will decrease by one-third. In the present context the recent advancement of nano-scale science and engineering is opening up a hitherto unknown and novel gateway to the 
development and deployment of water purification processes. Nano-science is the study of phenomenon and manipulation of materials at atomic, molecular and macromolecular scales, where properties differ significantly from those at a larger scale (Shah and Ahmed, 2011). In recent years, a great deal of attention has been focused onto the applicability of nanostructured materials as adsorbents or catalysts in order to remove toxic and harmful substances from wastewater (Savage and Diallo, 2005). Nano-adsorbents had gained special attention since last decade because the materials of such kind possess unique properties than the bulk materials. Like different nano-materials, single and multi-metal or doped metal oxides are also subject of much interest since that materials possess high surface-to-volume ratio, enhanced magnetic property, special catalytic properties etc (Gupta et al., 2011). Consequently, different methods viz. chemical precipitation, sol-gel, vapour deposition, solvo thermal, solid state reaction etc were adopted for the synthesis of specified oxides by various researchers (Zhang, 2003).

Advances in nanoscale science and engineering suggest that many of the current problems involving water quality could be resolved or greatly diminished by using nanoadsorbents, nanocatalysts, bioactive nanoparticles, nanostructured catalytic membranes, nanotubes, magnetic nanoparticles, granules, flake, high surface area metal particle supra molecular assemblies with characteristic length scales of 9-10 nm including clusters, micro molecules, nanoparticles and colloids have a significant impact on water quality in natural environment (Mamadou and Savage, 2005). The defining factor which characterizes the capability of nanoparticles as a versatile water remediation tool includes their very small particle sizes $(1-100 \mathrm{~nm})$ in comparison to a typical bacterial cell which has a diameter on the order of $1 \mu \mathrm{m}(1000 \mathrm{~nm})$. Hence nanoparticles can be transported effectively by the groundwater flow (Zhang, 2003). As a result, nanoparticles can be anchored onto a solid matrix such as a conventional water treatment material like activated carbon and zeolite for enhanced water treatment (Zhang, 2003).

Nanotechnology has been considered effective in solving water problems related to quality and quantity (Bottero et al., 2006). Nanomaterials are contributing to the development of more efficient treatment processes among the advanced water systems (Obare and Meyer, 2004). There are many aspects of nanotechnology to address the multiple problems of water quality in order to ensure the environmental stability. This study provides a unique perspective on basic research of nanotechnology for water/wastewater treatment and reuse by focusing on challenges of future research.

\section{Role of nano-adsorbents in water/waste water treatment}

Nano-adsorbents are fast emerging as potent candidates for water/wastewater treatment in place of conventional technologies which, notwithstanding their efficacy, are often very expensive and time consuming (Amin et al., 2014). This would be in particular, immensely beneficial for developing nations like India where cost of implementation of any new removal process could become an important criterion in determining its success. Qualitatively speaking nano-adsorbents can be substituted for conventional materials that require more raw materials, are more energy intensive to produce or are known to be environmentally harmful (Bhattacharya et al., 2013). Employing green chemistry principles for the production of nano-adsorbents can lead to a great reduction in waste generation, less hazardous chemical syntheses, and an 
inherently safer chemistry in general. There is also a wide debate about the safety of nanoadsorbents and their potential impact on the environment. There is fervent hope that nanotechnology can play a significant role in providing clean water to the developing countries in an efficient, cheap and sustainable way (Gupta et al., 2011).

\section{Mechanisms of removing pollutants from wastewater by nano-adsorbents}

Two vital properties make nanoparticles highly lucrative as adsorbents. On a mass basis, they have much larger surface areas compared to macro particles. They can also be enhanced with various reactor groups to increase their chemical affinity towards target compounds (Tiwari et al., 2008). Many materials have properties dependent on size. Hematite particles with a diameter of $7 \mathrm{~nm}$, for example, adsorbed $\mathrm{Cu}$ ions at lower $\mathrm{pH}$ values than particles of 25 or $88 \mathrm{~nm}$ diameter, indicating the enhanced surface reactivity for iron oxides particles with decreasing diameter (Nowack and Bucheli, 2007).

Peng et al., (2005) have developed a novel sorbent with high surface area $\left(189 \mathrm{~m}^{2} / \mathrm{g}\right)$ consisting of cerium oxide supported on carbon nanotubes $\left(\mathrm{CeO}_{2}-\mathrm{CNTs}\right)$. Deliyanni et al., (2003) have also synthesized and characterized a novel As (V) sorbent consisting of akaganeite $(\beta-\mathrm{FeOOH})$ nanocrystals, for the removal of metals and other inorganic ions, mainly nanosized metal oxides. Equilibrium adsorption of As (III) and As (V) by nanocrystalline $\mathrm{TiO}_{2}$ occurred within 4 hours and the adsorption followed pseudo-second-order kinetics in experiments conducted by Peng et al., (2005). Bang et al., (2004) reported that equilibrium was reached in 63 minutes for adsorption of As (V) adsorption and 240 minutes for adsorption of As (III). Manna et al., (2004) investigated the removal of As (III) using a synthesized crystalline hydrous titanium dioxide. They found that $70 \%$ of As (III) adsorption occurred within the first 30 minutes of contact time. Nano-agglomerates of mixed oxides such as iron-cerium, iron-manganese, ironzirconium, iron-titanium, iron-chromium, cerium-manganese etc. have been synthesized and successfully employed for pollutant removal (i.e. arsenic, fluoride etc.) from aqueous solutions (Boronina et al., 1995). Metals such as zinc and tin possess similar reduction capabilities of iron (Boronina et al., 1995). Like iron, these metals are converted to metal oxides in the decontamination process. Other metals have been combined with iron as well to produce similar results. Both iron-nickel and iron-copper bimetallic particles have been demonstrated to degrade trichloro-ethane and trichloro-ethene (Lien and Zhang, 2001). Bissen et al., (2001) have showed that photo-oxidation of As (III) to As (V) occurs within minutes. No reverse reaction of As (V) to As (III) was observed, and while As (III) was oxidized by UV light in the absence of $\mathrm{TiO}_{2}$, the reaction was way too slow to be feasible in water treatment.

Carbon is a versatile adsorbent that is heavily used in the removal of various pollutants including heavy metals from aqueous solutions. Graphene is the latest member of the carbon family in research and is believed to be one of the most potential materials for water treatment (Babel and Kurniawan, 2003). Graphene is a flat, sp2-hybridized, two-dimensional honeycomb arrangement of carbon atoms with single carbon atom thickness (Park and Ruoff, 2009). Features like large surface area and presence of surface functional groups make them attractive adsorbent candidates for water purification (Sreeprasad et al., 2011). RGO-magnetite and GO-ferric hydroxide composites were used for the removal of arsenic from water (Chandra et al., 2010; Zhang et al., 2010). Iron based oxides and hydroxides are already 
proved as effective materials for removing arsenic from drinking water (Zhang et al., 2010). Interestingly, reduced graphene oxide also has antibacterial property and this property may help in preventing the development of biofilm on the filter surface due to bacterial growth, which can cause unwanted tastes and odors or prematurely clogging of filters (Hu et al., 2010).

While nanotechnology is considered to be the new buzzword by many in the scientific community, information regarding the subject remains largely dispersed and fragmented due to the relative novelty of the technology. But the increasing trends of researches which have been discussed so far have made it clear that nanotechnology holds an immense potential to be developed into a very potent water treatment tool of the 21 st century. In fact nanomaterials and their various incarnations are the drivers for the nanotechnology revolution. On a positive note, due to their extremely high potential in combination with the high specificity, nanoadsorbents can be developed into ideal candidates for water treatment and may contribute to solving future challenges in the area of water treatment technologies. Thus nanotechnology holds a lot of promise in the remediation of groundwater and for this there is further scope in research and development.

\section{Acknowledgement}

The authors acknowledge their heartfelt gratitude to Department of Processing and Food Engineering, College of Agricultural Engineering, University of Agricultural Sciences, Raichur, Karnataka, India.

\section{References}

Amin, M. T., Alazba, A. A. and Manzoor, U., 2014. A review of removal of pollutants from water/wastewater using different types of nanomaterials. Adv. Mater. Sci. Eng. 1(5):125-146.

Ashbolt, N. J., 2004, Microbial contamination of drinking water and disease outcomes in developing regions, J. Toxicology., 1(3): 229-238.

Babel, S., and Kurniawan, T. A., 2003, Low-cost adsorbents for heavy metals uptake from contaminated water: A review. J. Hazardous Materials, 97: 219-243.

Bang, J. J., Guerrero, P. A., Lopez, D. A., Murr, L. E. and Esquivel, E. V., 2004, Carbon nanotubes and other fullerene nanocrystals in domestic propane and natural gas combustion streams. J. Nanoscience and Nanotechnol, 4: 716-718.

Bhattacharya, S., Saha, I., Mukhopadhyay, A., Chattopadhyay, D., Ghosh, U. C. and Chatterjee, D., 2013, Role of nanotechnology in water treatment and purification: Potential applications and implications. Int. J. Chem. Sci. Technol., 3(3): 59-64.

Bissen, M., Vieillard-Baron, M. M., Schindelin, A. J. and Frimmel, F. H., 2001, $\mathrm{TiO}_{2-}$ catalyzed photooxidation of arsenite to arsenate in aqueous samples. $J$. Chemosphere., 44(4): 751-757.

Boronina, T., Klabunde, K. and Sergeev, G., 1995, Destruction of organohalides in water using metal particles-carbon tetrachloride/water reactions with magnesium, tin and zinc. Env. Sci. Technol., 29 (6): 1511-1517.

Bottero, J. Y., Rose, J. and Wiesner, M. R., 2006, Nanotechnologies: tools for sustainability in a new wave of water treatment processes. Int. Env. Asses. Manage, 2:4:391-395.

Chandra, V., Park, J., Chun, Y., Lee, J. W., Hwang, I. C. and Kim, K. S., 2010, Waterdispersible magnetite-reduced graphene oxide composites for arsenic removal. ACS Nano., 4: 3979-3986.

Deliyanni, E. A., Bakoyannakis, D. N., Zouboulis, A. I. and Matis, K. A., 2003, Sorption of $\mathrm{As}(\mathrm{V})$ ions by akaganeite-type nanocrystals. Chemosphere, 50(1): 155-163.

Gupta, K., Bhattacharya, S., Chattopadhyay, D. J., Mukhopadhyay, A., Biswas, H., Dutta, J., Roy, N. R. and Ghosh, U. C., 2011, Ceria associated manganese oxide nanoparticles: Synthesis, characterization and $\operatorname{arsenic}(\mathrm{V})$ 
sorption behavior. J. Chem. Eng., 172: 219229.

Hu, W., Peng, C., Luo, W., Lv, M., Li, X., Li, D., Huang, Q and Fan, C., 2010, Graphene-based antibacterial paper. ACS Nano., 4: 43174323.

Hutton, G., Haller, L. and Bartram, J., 2007, Economic and health effects of increasing coverage of low cost household drinking water supply and sanitation interventions. World Health Organization.

Leonard, P., Hearty, S and Brennan, J., 2003, Advances in biosensors for detection of pathogens in food and water. Enzyme and Microbial Technol., 32(1): 3-13.

Lien, H., and Zhang, W., 2001, complete dechlorination of chlorinated ethenes with nanoparticles. J. Colloids Surfaces, 191: 97105.

Mamadou, S. D., and Savage, N., 2005, Nanoparticles and water quality. J. Nano. Research, 7: 325-330.

Manna, B., Dasgupta, M and Ghosh, U. C., 2004, Crystalline hydrous titanium (IV) oxide (CHTO): An arsenic (III) scavenger. $J$. Water Supply Res. Technol., 53(7): 483-495.

Nowack, B., and Bucheli, T. D., 2007, Occurrence behavior and effects of nanoparticles in the environment. Env. Pollution, 150: 5-22.

Obare, S. O., and Meyer, G. J., 2004, Nanostructured materials for environmental remediation of organic contaminants in water. J. Env. Sci. Health., 39(10): 25492582.

Park, S. and Ruoff, R. S., 2009, Chemical methods for the production of graphenes. Nature Nanotechnol, 4: 217-224.

Peng, X., Luan, Z., Ding, J., Di, Z., Li, Y. and Tian, B., 2005, Ceria nanoparticles supported nanotubes for the removal of arsenate from water. J. Materials Letters, 59: 399-403.

Savage, N., and Diallo, M. S., 2005, Nanomaterials and water purification: Opportunities and challenges. $J$. Nanoparticle Res., 7: 331-342.

Shah, M. A., and Ahmed, T., 2011, Principles of Nanoscience and Nanotechnology. Narosa Publishing House, New Delhi, India, pp. 3447.

Sreeprasad, T. S., Maliyekkal, S. M., Lisha, K. P. and Pradeep, T., 2011, reduced graphene oxide-metal/metal oxide composites: Facile synthesis and application in water purification. J. Hazardous Materials, 186: 921-931.

Tiwari, D. K., Behari, J. and Sen, P., 2008, Applications of nanoparticles in wastewater treatment. J. World Applied Sci., 3(3): 417433.

World Health Organization and UNICEF, 2013, Progress on sanitation and drinking-water. World Health Organization, Geneva, Switzerland.

Zhang, K., Dwivedi, V., Chi, C. and Wu, J., 2010, Graphene oxide/ferric hydroxide composites for efficient arsenate removal from drinking water. J. Hazardous Materials, 182: 162168.

Zhang, S., Li, X. Y. and Chen, J. P., 2010, Preparation and evaluation of a magnetitedoped activated carbon fiber for enhanced arsenic removal. J. Carbon., 48: 60-67.

Zhang, W. X., 2003, Nano-scale iron particles for environmental remediation: an overview. $J$. Nanoparticle research, 5: 323-332.

Zhang, W. X., 2003, Nano-scale iron particles for environmental remediation: an overview. $J$. Nanoparticle research, 5: 323-332.

\section{How to cite this article:}

Dinesha, B.L., H. Sharanagouda, N. Udaykumar, C., T. Ramachandr and Anil B. Dandekar. 2017. Removal of Pollutants from Water/Waste Water Using Nano-Adsorbents: A Potential Pollution Mitigation. Int.J.Curr.Microbiol.App.Sci. 6(10): 4868-4872.

doi: https://doi.org/10.20546/ijcmas.2017.610.455 